\title{
Identifikasi Pengaruh Kondisi Lingkungan Fisik terhadap Kuantitas Air Telaga Palgading di Ekosistem Karst (Studi Kasus di Dusun Dulisen, Desa Giripurwo, Kecamatan Purwosari, Kabupaten Gunung Kidul, Provinsi DIY)
}

\author{
Rudy Yoga Lesmana \\ Program Studi Teknik Lingkungan Universitas Muhammadiyah Palangkaraya \\ email: yogalesmana96@yahoo.com
}

\begin{abstract}
ABSTRAK. Dusun Dulisen sangat tergantung dengan adanya Telaga palgading sebagai sumber penghidupan selain dari air hujan. Penelitian ini bertujuan mengidentifikasi pengaruh kondisi lingkungan fisik terhadap kuantitas air di telaga palgading dan faktor-faktor yang menjadi pengontrol dan pemicu kuantitas air tersebut, serta arahan pengelolaan agar kuantitas air telaga tetap terjaga. Metode penelitian yang digunakan adalah metode survey dan pemetaan, meliputi tahap kerja lapangan, analisis data dan pembuatan laporan. Data yang diperoleh berupa data primer lapangan dan data sekunder dari berbagai referensi. Hasil penelitian menunjukan bahwa di daerah penelitian yang berperan sebagai faktor pemicu ketersediaan air telaga palgading meliputi curah hujan, penggunaan lahan, erosi dan jumlah penduduk sedangkan kemiringan lereng, satuan batuan dan tebal tanah merupakan faktor pengontrol terhadap terhadap ketersediaan air telaga. Pada kondisi hujan luas telaga palgading yaitu $11.524,8 \mathrm{~m}^{2}$, pada saat kering yaitu $6.948,8 \mathrm{~m}^{2}$ dan mempunyai selisih volume air telaga sebesar $4.219,38 \mathrm{~m}^{3} /$ tahun, tinggi muka air telaga pada saat hujan sebesar 9,3 m dan $8,1 \mathrm{~m}$ pada saat tidak hujan, sehingga didapat volume air telaga pada waktu musim hujan yaitu 10.968,08 $\mathrm{m}^{3}$ dan $6.748,7 \mathrm{~m}^{3}$ pada saat musim kemarau. Volume telaga palgading saat kondisi konstan setiap tahunnya adalah $88.584 \mathrm{~m}^{3}$. Input air hujan pada luasan daerah tangkapan air/catchment area seluas 233.684,407 $\mathrm{m}^{2}$ yaitu sebesar 238.786 $\mathrm{m}^{3} /$ tahun. Berdasarkan hasil perhitungan didapat jumlah air yang hilang sebesar $5.959,337 \mathrm{~m}^{3}$. Jumlah air yang lolos ini diakibatkan oleh adanya evapotranspirasi, volume telaga konstan dan pengambilan air hujan terhadap curah hujan yang masuk pada daerah tangkapan air. Penyusutan volume air di telaga dengan mengurangi $3,6186 \%$ dari volume air telaga palgading. Arahan pengelolaan untuk telaga palgading yaitu dengan konsep Eko-Hidraulik alami yang dilakukan dengan memaksimalkan fungsi vegetasi sebagai penyeimbang pasokan air yang ada pada daerah tangkapan air di telaga palgading. Penanaman vegetasi dalam konsep ini tidak boleh ditanam terlalu dekat dengan bagian tepi telaga.
\end{abstract}

Kata kunci: Sistem Informasi Lingkungan (SIL), Sampah, Kontinyuitas

\section{PENDAHULUAN}

Ekosistem perbukitan karst di wilayah Kabupaten gunung kidul dikenal luas oleh masyarakat sebagai daerah yang kekurangan air terutama pada musim kemarau, padahal curah hujan rata-rata wilayah ini cukup untuk pemenuhan ketersediaan air sehari-hari, dan keadaan seperti ini sudah umum terjadi di daerah karst yang pada umumnya terdiri dari batu gamping atau batu kapur yang memiliki 
resapan air yang sangat tinggi. Kebutuhan air untuk kegiatan domestik di daerah kecamatan purwosari khususnya sangat besar, selain itu pada musim hujan para penduduk biasanya memenfaatkan air hujan untuk keperluan sehari-hari yang ditampung pada bak penampungan sebagai antisipasi untuk menghadapi musim kemarau yang sangat sulit untuk mendapatkan air.

Pada musim kemarau biasanya para penduduk banyak yang memanfaatkan air telaga (lokva) untuk keperluan domestik , karena air telaga ini merupakan penyedia air utama pada waktu musim kemarau, tetapi seiring besarnya keperluan penduduk terhadap air telaga dan masalah kekeringan lainnya yang sudah menjadi hal yang umum terjadi dikabupaten Gunung Kidul menyebabkan kuantitas air telaga yang dirasakan oleh penduduk semakin menyusut atau semakin berkurangnya jumlah air telaga. Oleh karena itu, dapat digambarkan telah terjadi penurunan kuantitas air telaga di ekosistem karst Kabupaten Gunung Kidul.

\section{TUJUAN PENELITIAN}

a. Untuk mengetahui karakteristik lingkungan fisik daerah penelitian.

b. Untuk mengetahui menegtahui faktor pengeontrol dan pemicu terjadinya penurunan kuantitas air telaga berdasarkan lingkungan fisik di daerah penelitian.

c. Memberikan arahan pengelolaan agar dapat mengurangi permasalahan penurunan kuantitas air telaga di daerah penelitian

\section{KAJIAN PUSTAKA Identifikasi}

Identifikasi adalah sebuah usaha untuk mengenali sesuatu berdasarkan apa yang ada. Pengidentifikasian biasanya hanya berdasar pada atau berhenti pada apa yang ada atau sering disebut apa adanya, sesuatu itu dengan mudah dapat terlihat oleh mata telanjang.

\section{Karst}

Karst adalah suatu kawasan ynag mempunyai karakteristik relief dan drainase yang khas, yang disebabkan keterlarutan batuannya yang tinggi. Karst pada umumnya membentuk bentang alam yang ditandai oleh terdapatnya dekokan (Closed depressions) dengan berbagai ukuran dan susunan, pengasatan bawah tanah (Prastistho, 1995 dalam Kusumayudha, 2004).

\section{Dolina}

Salah satu ciri khas bentang alam karst adalah bahwa setiap lereng biasanya berakhir pada suatu depresi yang tertutup tanpa saluran keluar bagi air. Satu-satunya jalan keluar bagi air yang terperangkap pada depresi tersebut hanya bawah permukaan. Depresi tertutup yang pada umumnya serupa mangkok, termasuk kedalam klasifikasi relief negatif pada bentang alam karst. Dolina atau sinkhole merupakan bentuk cekung membundar atau depresi tertutup di permukaan, yang berbentuk seperti mangkok, dengan garis tengah mulai dari beberapa meter sampai $1000 \mathrm{~m}$. kedalaman sebuah dolina dapat mulai dari sangat dangkal (kurang dari $1 \mathrm{~m}$ ), hingga ratusan meter. Dolina terbentuk karena proses pelarutan, colaps, suffusions, proses subsident atau runtuhnya gua yang berada di bagian bawah dolina tersebut. Dolina yang membawa air dari permukaan ke bawah permukaan, melalui pembuluh yang terlebarkan, atau melalui tanah menuju ke sistem/jaringan saluran bawah tanah (gua) di bawah permukaan (White, 1988)

\section{Lokva (Telaga)}

Dolina juga dapat di definisikan sebagai bentuk morfologi pada wilayah karst yang berbentuk cekungan seperti mangkuk, kerucut atau tabung yang dapat dibentuk oleh daya air yang dapat melarutkan batuan gamping atau amblesan bawah tanah. Apabila sebagian besar dolina dilapisi oleh sedimen kedap air maka cekungan ini akan terisi dan membentuk lokva. Lokva di gunungsewu lebih dikenal oleh penduduk setempat sebagai telaga. Apabila suatu saat bagian dasar dari lokva ini karena alasan pendangkalan, kemudian digali hingga seluruh atau sebagian lapisan kedapnya hilang maka lokva dapat mengalami kebocoran. Air lokva terserap kedalam tanah, dan telaga menjadi kering (Kusumayudha, 2004) 


\section{METODE PENELITIAN}

Penelitian mengenai pengaruh kondisi lingkungan terhadap kuantitas air telaga di Ekosistem Karst, Dusun Dulisen, Desa Giripurwo, kabupaten Gunung kidul dan sekitarnya menggunakan metode survey dan pemetaan,serta metode penampalan/tumpang susun (overlay) peta.

\section{Lokasi dan Waktu Penelitian}

Penelitian dilakukan di Dusun Dulisen,

Desa Giripurwo, Kecamatan Purwosari, Kabupaten Gunung Kidul, Daerah Istimewa Yogyakarta

\section{Tahap Penelitian}

Dalam teknik untuk memperoleh data primer dan data sekunder, pneliti akan melakukan beberapa tahapan. Secara garis besar tahapan penelitian dapat dikelompokkan menjadi lima tahap, yaitu:

1. Tahap persiapan

2. Tahap kerja lapangan

3. Tahap analisis data

4. Tahap evaluasi

5. Tahap penyusunan hasil laporan

\section{HASIL DAN PEMBAHASAN}

\section{Evaluasi Parameter Lingkungan Fisik}

Komponen lingkungan yang diperkirakan mengelami perubahan mendasar atau diperkirakan terjadinya hubungan sebab akibat, antara lingkungan fisik dengan ketersedian air di telaga palgading.

\section{Iklim}

Untuk kondisi hujan luas telaga palgading yaitu $11.524,8 \mathrm{~m} 2 /$ tahun dan pada saat kering yaitu 6.947,8 m2/tahun, kedalaman telaga palgading pada saat hujan yaitu $9,3 \mathrm{~m}$ dan $8,1 \mathrm{~m}$ pada saat tidak hujan sehingga didapat volume air telaga palgading pada waktu musim hujan yaitu 10.968,08 m3/tahun dan pada saat musim kemarau menjadi $6.748,7 \mathrm{~m} 3 /$ tahun dan mempunyai selisih volume air sebesar 4.219,38 m3/tahun. Untuk volume telaga palgading pada saat konstan untuk setiap tahunnya yaitu 88.584 m3/tahun. Volume air telaga akan berkurang pada musim kemarau, karena hujan sangat sedikit atau sama sekali tidak turun hujan. Air hujan dapat dikatakan sebagai faktor penyebab dari ketersedian air telaga palgading, karena tidak ada sumber air yang lain untuk pasokan air telaga, selain air hujan. Input air hujan untuk luas tangkapan air/catchment area $0,23368 \mathrm{~km} 2$ yaitu sebesar $346,82 \mathrm{~m} 3$.

\section{Bentuk Lahan}

Bentuk lahan yang berbukit-bukit disekitar telaga palgading dan didominasi dengan lereng yang curam sangat membantu dalam proses perjalanan air di atas permukaan tanah, semakin curam lerengnya maka proses air larian tersebut semakin cepat, sehingga diperlukan waktu yang singkat untuk mengisi telaga palgading tersebut hingga penuh. Jadi dapat dikatakan bentuklahan sebagai faktor pengontrol ketersedian air di telaga palgading.

\section{Tanah}

Kehilangan air hujan akibat proses infiltrasi sangat kecil, karena dari tanah yang ada di daerah tersebut didominasi oleh tekstur lempung. Lempung mempunyai tekstur yang sangat halus dengan sifat mengembang bila basah, sehingga dapat dikatakan sebagai lapisan kedap air, dan tanah lempung yang berada di dasar telaga tersebut sangat berperan dalam proses sementasi pada bagian dasar telaga, sehingga air hujan yang masuk ke telaga tidak akan lolos kebawah permukaan tanah.

Kondisi di sekitar telaga palgading yang didominasi tekstur tanah lempung sangat berperan baik dalam menampung air telaga, semakin banyak kandungan lempungnya, maka semakin banyak pori-pori telaga yang tertutup akibat proses sementasi, selama masyarakat ataupun pemerintah tidak melakukan pengerukan material-material pada dasar telaga, jadi dapat dikatakan bahwa tanah merupakan faktor pemicu dari ketersediaan air telaga palgading kerena jika tidak ada material lempung di dasar telaga maka air hujan tidak akan tertampung dan akan langsung lolos ke bawah tanah.

\section{Analisis Erosi Tanah}

Berdasarkan penelitian erosi di lapangan, telaga palgading memiliki tingkatan 
erosi yang berbeda-beda, tetapi ada sebagian wilayah telaga yang mengalami erosi cukup parah, yaitu terletak disebelah barat telaga palgading dan memiliki tingkat bahaya erosi $>480$ ton/tahun/ha. Hal ini merupakan tingkat bahaya erosi yang paling besar dibandingkan dengan wilayah sekitar telaga palgading lainnya, dengan adanya erosi tersebut maka dikhawatirkan umur telaga akan menjadi pendek, karena setiap tahunnya tanah akan masuk ke dasar telaga palgading untuk lebih lanjutnya lihat tabel 1.

Tabel 1. Satuan Lahan untuk laju Erosi

\begin{tabular}{|c|c|c|c|c|c|c|c|}
\hline No & $\begin{array}{l}\text { Satuan } \\
\text { Lahan } \\
\end{array}$ & $\mathbf{R}$ & $\mathbf{K}$ & Ls & C & $\mathbf{P}$ & $\begin{array}{c}\text { A (Erosi) } \\
\text { Ton/ha/thn }\end{array}$ \\
\hline 1 & BLPSC1 & 878,25 & 0,46 & 12,00 & 0,01 & 0,04 & 1,93 \\
\hline 2 & BLPSC2 & 878,25 & 0,46 & 12,00 & 0,012 & 0,40 & 23,27 \\
\hline 3 & BLPSC 3 & 878,25 & 0,46 & 12,00 & 0,7 & 0,15 & 509,03 \\
\hline 4 & BLPC4 & 878,25 & 0,46 & 9,50 & 0,8 & 0,15 & 460,55 \\
\hline 5 & TLPC & 878,25 & 0,46 & 9,50 & 0,8 & 0,04 & 122,81 \\
\hline 6 & TLPAC & 878,25 & 0,46 & 4,25 & 0,7 & 0,008 & 9,61 \\
\hline 7 & BLAC & 878,25 & 0,46 & 9,50 & 0,01 & 0,40 & 15,35 \\
\hline 8 & HLDAC & 878,25 & 0,46 & 4,25 & 0,016 & 0,40 & 10,98 \\
\hline 9 & HLDC & 878,25 & 0,46 & 9,50 & 0,016 & 0,04 & 2,45 \\
\hline 10 & SLC & 878,25 & 0,46 & 9,50 & 0,01 & 0,04 & 1,53 \\
\hline 11 & TLC & 878,25 & 0,46 & 9,50 & 0,405 & 0,04 & 62,17 \\
\hline 12 & SLPC & 878,25 & 0,46 & 9,50 & 0,01 & 0,04 & 1,53 \\
\hline
\end{tabular}

\section{Satuan Batuan}

Satuan batuan dapat dikatakan sebagai faktor pengontrol kuantitas air telaga palgading, karena air hujan yang akan turun akan mengalir melewati rongga-rongga, selain itu dengan adanya lapisan pada batugamping dengan pori-pori besar, maka semakin besar dalam meloloskan air, selain itu batugamping tersebut terlapisi oleh tanah lempung yang mempunyai porositas yang buruk dan menjadi media dalam proses sedimentasi di dasar telaga palgading.

Jenis batuan yang dominan yang terdapat di telaga palgading yaitu jenis batugamping klastik, warna segar putih (lapuk kehitaman), struktur berlapis, ukuran butir pasir, porositas baik tersemenkan oleh karbonat, komposisi mineral kalsit dan dapat disebut sebagai batuan kalkarenit. Berikut adalah arah kemiringan batuan yang berpengaruh terhadap laju aliran permukaan yang diakibatkan air hujan yang berada di sekitar telaga palgading (Tabel 2)

Tabel 2. Pengukuran arah kedudukan batuan

\begin{tabular}{cccc}
\hline No & $\mathbf{X}$ & $\mathbf{X}$ & Strike/dip \\
\hline 1 & 431897 & 9111343 & N $245^{\circ} / 15^{\circ} \mathrm{E}$ \\
2 & 432771 & 9111565 & N $175^{0} / 30^{\circ} \mathrm{E}$
\end{tabular}

Tabel 2. Lanjutan

\begin{tabular}{|c|c|c|c|}
\hline No & $\mathbf{X}$ & $\mathbf{X}$ & Strike/dip \\
\hline 3 & 431779 & 9111490 & $\mathrm{~N} 160^{0} / 43^{\circ} \mathrm{E}$ \\
\hline 4 & 432024 & 9111328 & $\mathrm{~N} 90^{\circ} / 35^{\circ} \mathrm{E}$ \\
\hline 5 & 432015 & 9111267 & $\mathrm{~N} 60^{\circ} / 25^{\circ} \mathrm{E}$ \\
\hline 6 & 431833 & 9111087 & $\mathrm{~N} 292^{\circ} / 70^{\circ} \mathrm{E}$ \\
\hline 7 & 431833 & 9111139 & $\mathrm{~N} 230^{\circ} / 35^{\circ} \mathrm{E}$ \\
\hline 8 & 431844 & 9111447 & $\mathrm{~N} 115^{\circ} / 11^{0} \mathrm{E}$ \\
\hline 9 & 431763 & 9110954 & $\mathrm{~N} 190^{\circ} / 34^{\circ} \mathrm{E}$ \\
\hline 10 & 431848 & 9111389 & $\mathrm{~N} 82^{\circ} / 25^{\circ} \mathrm{E}$ \\
\hline 11 & 431727 & 9111267 & $\mathrm{~N} 220^{\circ} / 15^{\circ} \mathrm{E}$ \\
\hline
\end{tabular}

\section{Penggunaan Lahan}

Penggunaan lahan di daerah penelitian yaitu semak belukar, tegalan, hutan, sawah tadah hujan dan permukiman. Komponen penggunaan lahan berupa semak belukar dan tegalan, mendominasi wilayah sekitar telaga palgading. jika ditelaah lebih jauh maka untuk mempertahankan kuantitas air telaga perlu dilakukan penanaman vegetasi-vegetasi seperti jati, albasia dan juga beringin, karena pohon-pohon tersebut dapat mempertahankan keseimbangan dari air telaga palgading, penahan sedimen yang berasal dari adanya erosi di pinggir telaga, dan juga dapat menambah keasrian dari telaga tersebut. Jadi jelas kalau komponen penggunaan lahan dapat dikatakan sebagai pemicu dari ketersediaan jumlah air telaga palgading.

\section{Pendangkalan Telaga}

Berdasarkan hasil perhitungan didapat luas telaga palgading yaitu sebesar 11.524,8 $\mathrm{m} 2$ atau 1.15248 ha, erosi terbesar terjadi pada bagian barat telaga yaitu sebesar 560,67 ton/ha/tahun, sehingga jika luas telaga dikali dengan besarnya erosi, maka luas telaga yang tertutupi tanah akibat erosi adalah 645,38 ton/ha/tahun, dan hal ini merupakan faktor pemicu terjadinya pendangkalan pada permukaan telaga palgading.

\section{Kebocoran Telaga}

Kebocoran dapat dikatakan sebagai faktor pemicu dari ketersediaan air telaga, yaitu dengan melihat adanya lapies pada batuan yang ada disekitar telaga palgading. Berdasarkan hasil perhitungan didapat jumlah air yang hilang yaitu sebesar 254.852,319 $\mathrm{m} 3 /$ th. Jumlah air yang lolos ini diakibatkan oleh adanya evapotranspirasi, volume telaga konstan dan pengambilan air hujan terhadap curah hujan yang masuk pada daerah tangkapan air. 


\section{Kepadatan Penduduk}

Kepadatan penduduk dapat dikatakan sebagai faktor pengontrol dari ketersediaan air telaga palgading, karena terjaganya jumlah air telaga tergantung dari peran serta masyarakat dalam merawat telaga tersebut dari kerusakan. Yang menjadi perhatian adalah apabila penduduk yang ada disekitar telaga palgading tidak menjaga kondisi lingkungan sekitar tetap baik maka dikhawatirkan akan memperpendek umur telaga palgading.

Dengan adanya penebangan pohon yang terjadi di ekosistem karst telaga palgading maka dikhawatirkan akan menyebabkan berkurnagnya pengontrol sedimen yang akan masuk ke telaga. Selain itu fungsi dari tanaman adalah sebagai penyimpan air yang baik.

\section{Kebutuhan Air Per Orang Per Hari}

Untuk kebutuhan air masyarakat dari telaga palgading sebenarnya tidak terlalu besar. Untuk kebutuhan air per orang per hari di sekitar telaga palgading yaitu 34,85 liter, hal ini karena masyarakat menggunakan air tersebut hanya untuk mandi dan cuci ketika mereka selesai dari sawah. Untuk cuci dan memandikan ternak penggunaan airnya tidak terlalu besar karena tidak membawa pulang air telaga tersebut.

Dari 34,85 liter dan dengan jumlah penduduk sekitar 252 jiwa, maka dalam setahun air telaga yang diambil masyarakat sebesar 3.205,503 m3/tahun dan sama saja dengan mengurangi 3,6186\%/tahun dari volume air telaga palgading konstan.

Tabel 3. Kebutuhan air penduduk di sekitar Telaga

\begin{tabular}{clccccc}
\hline & & Jumlah & \multicolumn{3}{c}{ Kebutuhan (liter) } & \multirow{2}{*}{$\begin{array}{c}\text { Rerata } \\
\text { No }\end{array}$} \\
& Nama & $\begin{array}{c}\text { Anggota } \\
\text { keluarga }\end{array}$ & Mandi & Cuci & Jumlah & $\begin{array}{c}\text { kebuhan } \\
\text { air/org/hari }\end{array}$ \\
\hline 1 & Sumiran & 5 & 70 & 60 & 120 & 26 \\
2 & Suraji & 2 & 40 & 30 & 70 & 35 \\
3 & Parjono & 3 & 60 & 45 & 105 & 35 \\
4 & Sutikno & 4 & 70 & 60 & 130 & 32,5 \\
5 & Maryono & 3 & 50 & 40 & 90 & 30 \\
6 & Parmi & 4 & 70 & 50 & 120 & 30 \\
7 & Lastri & 2 & 60 & 30 & 90 & 45 \\
8 & Sutarjo & 2 & 45 & 30 & 75 & 37,5 \\
9 & Wijatmoko & 4 & 70 & 60 & 130 & 32,5 \\
10 & Ismudadi & 2 & 60 & 30 & 90 & 45 \\
\hline & Jumlah & 31 & 595 & 435 & 1030 & 348,5 \\
\hline & Rerata & 3,1 & 59 & 43 & 103 & 34,85 \\
\hline
\end{tabular}

Dari tabel diatas rerata kebutuhan air per org/hari 34,85 liter, sehingga perhitungan kebutuhan air dalam setahun untuk penduduk telaga palgading, yaitu

Rata-rata kebutuhan air $=34,85$ liter/hari Jumlah penduduk Dusun Dulisen 252 jiwa Kebutuhan air dalam satu tahun= jumlah kebutuhan air rata-rata per/hari $\mathrm{x}$ jumlah penduduk $\times 365=34,851 /$ hari $\times 365 \times 252=$ $3205,503 \mathrm{~m}^{3} / \mathrm{th}$

\section{Penyusutan Air Telaga}

Penyusutan air telaga didasarkan atas jumlah pengambilan air oleh penduduk terhadap total volume air telaga. Penyusutan air untuk telaga palgading adalah sebesar 3,6186\%/tahun dari jumlah konstan volume air telaga palgading sebesar $88.584 \mathrm{~m} 3 /$ tahun. Meskipun penyusutan air telaga sangat kecil, tapi dikhawatirkan lama-kelamaan air telaga akan berkurang karena pengambilan air tersebut.

\section{KESIMPULAN}

Berdasarkan hasil evaluasi penelitian yang telah dilakukan, maka dapat ditarik kesimpulan berikut.

1. Untuk kondisi hujan luas telaga palgading yaitu $11.524,8 \mathrm{~m}^{2}$ dan pada saat kering yaitu $6.947,8 \mathrm{~m}^{2}$, tinggi muka air telaga pada saat hujan yaitu sebesar 9,3 $\mathrm{m}$ dan 8,1 $m$ pada saat tidak hujan, sehingga didapat volume air telaga palgading pada waktu musim hujan yaitu 10.968,08 $\mathrm{m}^{3}$ dan $6.748,7 \mathrm{~m}^{3}$ pada saat musim kemarau serta mempunyai selisis volume air telaga sebesar 4.219,38 $\mathrm{m}^{3} /$ tahun.

2. Volume telaga palgading pada saat konstan untuk setiap tahunnya yaitu sebesar 88.584 $\mathrm{m}^{3} /$ tahun. Input air hujan untuk luasan daerah tangkapan air/catchment area seluas 233.684,407 $\mathrm{m}^{2}$ yaitu sebesar 238.784,34 $\mathrm{m}^{3} /$ tahun.

3. Luas telaga yang tertutupi tanah akibat erosi adalah 645,38 ton/ha/tahun, sehingga hal ini dapat dikatakan sebagai faktor pemicu terjadinya pendangkalan pada telaga palgading. 
4. Faktor pemicu ketersedian air telaga palgading meliputi curah hujan, penggunaan lahan, erosi dan jumlah penduduk, sedangkan kemiringan lereng, satuan batuan dan tebal tanah merupakan faktor pengontrol terhadap ketersedian air telaga.

5. Jumlah air yang hilang akibat kebocoran di daerah tangkapan air yaitu sebesar $84.845,643 \mathrm{~m}^{3} /$ tahun. Jumlah air yang lolos ini diakibatkan oleh adanya evapotranspirasi, volume telaga konstan dan pengambilan air hujan terhadap curah hujan yang masuk pada daerah tangkapan air.

6. Penyusutan air untuk telaga palgading adalah sebesar 3,6186\%/tahun dari jumlah konstan volume air telaga palgading sebesar $88.584 \mathrm{~m}^{3} /$ tahun.

\section{SARAN}

Saran yang dapat diberikan sehubungan dengan penelitian ini adalah sebagai berikut.

1. Penduduk setempatsenantiasa aktif menjaga kelangsungan dari umur telaga dengan memelihara lingkungan fisik disekitar telaga palgading sehingga ancaman kekeringan dapat teratasi.

2. Mengajukan usulan kepada pemerintah mengenai pengelolaan terhadap kuantitas air telaga palgading untuk menyelamatkan lingkungan yang telah dilakukan dalam bentuk dana kompensasi.

3. Perlu ikut serta bersama-sama melakukan konservasi air dengan cara menanam pohon-pohon disekitar telaga, hal ini dilakukan untuk pencegahan bahaya erosi.

4. Sebaiknya masyarakat tidak lagi memandikan ternak mereka dengan cara menceburkannya kedalam telaga. Hal ini demi untuk menjaga kualitas air telaga agar dapat dipergunakan sesuai peruntukannya.

5. Sebaiknya masyarakat membangun tempat penampungan air hujan yang lebih banyak lagi, agar dapat digunakan sebagai cadangan air pada saat musim kemarau disamping air telaga.

6. Sebaiknya pemerintah mensosialisasikan kepada masyarakat pentingnya fungsi dari telaga palgading sebagai salah satu sumber air utama selain air hujan.

7. Masyarakat disekitar telaga palgading sebaiknya tidak menebang pohon, karena dikhawatirkan akan memperpendek umur telaga

8. Perlu pemantauan secara berkala untuk mengetahui perkembangan penyusutan air.

\section{DAFTAR PUSTAKA}

Admajaya, 2007, Kajian kesesuain lahan untuk arahan pengembangan pertanian organik, Kecamatan Semanu, Kabupaten Gunung Kidul, Skripsi, Fakultas Geografi, Universitas Gadjah Mada, Yogyakarta.

Asdak, C., 1995, Hidrologi dan pengelolaan daerah aliran sungai, Gadjah Mada University Press. Yogyakarta.

BPS, Kabupaten Gunung kidul dalam angka tahun 2007/2008, Badan Pusat Statistik (BPS) Provinsi DIY

Keputusan presiden Republik Indonesia Nomor 32 tahun 1990 Tentang Pengelolaan Kawasan lindung.

Keputusan meneteri energi dan sumberdaya Mineral Nomor 1456.K/20/Mem/2000 Tentang pedoman pengelolaan kawasan karst

Kusumayudha, S.B., 2004, Hidrogeologi karst dan Geometri fraktal di daerah Gunungsewu, Adicita, Yogyakarta.

Reyes, L., 2007, Metode inventarisasi sumber Daya Lahan, Andi Offset, Yogyakarta.

Seyhan, E. 1993.'Dasar-Dasar Hidrologi, Gadjah Mada University Press, Yogyakarta

Undang-undang lingkungan Hidup Nomor 7 Tahun 2004 tentang Sumber Daya Air

Undang-Undang Republik Indonesia Nomor 26 Tahun 2007 Tentang Penataan Ruang

Undang-undang Republik Indonesia Nomor 32 Tahun 2009 tentang perlindungan dan pengelolaan lingkungan hidup.

Undang-undang Republik Indonesia Nomor 26 Tahun 2007 tentang rencanatata ruang wilayah nasional 
Peta Rupabumi digital indonesia 2001 lembar panggang", Badan Koordinasi Survey dan pemetaan nasional. Bandung.

Wartono, R., 1995, Peta Geologi Lembar Yogyakarta, Pusat Penelitian dan Pengembangan Geologi, Bandung
White, W. B., 1988, Geomorphology and Hydrology of karst Terrains, Oxford University Press, London.

Vestappen, 1983, Fractals in Engineering Geology Preface, Oxford University Press, London. 